CHAPTER

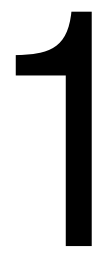

\title{
Exploring Methods in Managerial and Organizational Cognition: Advances, Controversies, and Contributions
}

Gerard P. Hodgkinson, Kristian J. Sund and Robert J. Galavan

\begin{abstract}
This book comprises the second volume in the recently launched New Horizons in Managerial and Organizational Cognition book series. Volume 1 (Sund, Galavan, \& Huff, 2016), addressed the topic of strategic uncertainty. This second volume comprises a collection of contributions that variously report new methodological developments in managerial and organizational cognition, reflect critically on those developments, and consider the challenges that have yet to be confronted in order to further advance this exciting and dynamic interdisciplinary field. Contextualizing
\end{abstract}

Methodological Challenges and Advances in Managerial and Organizational Cognition New Horizons in Managerial and Organizational Cognition, 2018, 1-22

Edited by Robert J. Galavan, Kristian J. Sund and Gerard P. Hodgkinson doi:10.1108/S2397-52102017002

Copyright (C) 2018 by Emerald Publishing Limited All rights of reproduction in any form reserved 
within an overarching framework the various contributions selected for inclusion in the present volume, in this opening chapter we reflect more broadly on what we consider the most significant developments that have occurred over recent years and the most significant challenges that lie ahead.

Keywords: Knowledge elicitation; management and organization theory; managerial and organizational cognition; organizational research methods

\section{Introduction}

More than a quarter of century has elapsed since the publication of Mapping Strategic Thought (Huff, 1990), an agenda-setting collection of chapters that laid the central methodological foundations of the managerial and organizational cognition (MOC) field. A number of those chapters have become citation classics. However, the world is now a very different place. Many social, political, economic, and technological developments have occurred over this period and, in consequence, the nature of work and the workplace have changed, and are continuing to change, dramatically. In what ways have these developments changed concomitantly the intellectual foci of MOC and the methods researchers are adopting to address the substantive issues at hand? To what extent are the MOC research methods that were in vogue in the final decade of the 20th century still relevant as a basis for tackling 21 st-century problems?

Reflecting the major changes occurring in the social and material world, the world of management and organization theory and research is now at a very different place. Accordingly, our primary purpose in editing this second volume of New Horizons in Managerial and Organizational Cognition was to assemble a collection of articles that individually and collectively take stock of the MOC field's methodological accomplishments and set the agenda for the next phase of its development. The chapters selected for inclusion offer variously state-of-the-art critical reflections on the issues highlighted above and report on the development and evaluation of new methodological techniques that are seeking to address them. 


\section{From Conscious to Nonconscious and Cold to Hot Cognition}

In order to contextualize the various contributions incorporated in the present volume, we will reflect briefly on a series of interrelated fundamental advances that have occurred in several of the constituent base disciplines underpinning the MOC field that are challenging and changing its methodological practices. Arguably, one of the biggest advances in the social and behavioral sciences over recent decades, which is having a major bearing on the development of MOC currently, is the rise of social neuroscience, in particular the rapidly developing specialist subfields of social cognitive neuroscience (Lieberman, 2007) and neuroeconomics (Loewenstein, Rick, \& Cohen, 2008). Building on these exciting developments and related advances in dual-process theories of reasoning, judgment, and social cognition (e.g., Chaiken \& Trope, 1999; Epstein, 1994; Evans, 2007, 2008; Kahneman, 2011; Sloman, 1996; Smith \& DeCoster, 2000; Stanovich \& West, 2000; Strack \& Deutsch, 2004), MOC is moving increasingly away from "cold cognition" conceptions of human information processing, focused primarily on revealing and analyzing actors' explicit representations of work-related knowledge (cf. Eden \& Spender, 1998; Fiol \& Huff, 1992; Hodgkinson \& Healey, 2008; Hodgkinson \& Sparrow, 2002; Huff, 1990; Huff \& Jenkins, 2002; Sparrow, 1998; Walsh, 1995), to consider the dynamic interplay of cognition and emotion at both conscious and nonconscious levels, and on an individual and collective basis (see, e.g., Ashkansey, Humphrey, \& Huy, 2017; Dane \& Pratt, 2007; Healey \& Hodgkinson, 2017; Hodgkinson \& Healey, 2011, 2014).

Two additional major bodies of interrelated work in social and organizational psychology that are fueling MOC's growing scholarly interest in the study of "nonconscious" processes (e.g., Healey, Vuori, \& Hodgkinson, 2015; Latham \& Piccolo, 2012; Shantz \& Latham, 2009) are centered on the analysis of implicit attitudes (Greenwald \& Banaji 1995; Greenwald, McGhee, \& Schwartz, 1998; Greenwald et al., 2002) and priming (Bargh \& Williams 2006; Bargh, Chen, \& Burrows, 1996; Ferguson \& Bargh, 2004). Like the aforementioned advances in social neuroscience and dual-process theories, inter-alia, these developments are revealing the inner workings of the "intuitive mind" (Dane \& Pratt, 2007; Hodgkinson, Langan-Fox, \& Sadler-Smith, 2008; Sadler-Smith, 2010) and leading scholars to rethink fundamentally 
taken for granted assumptions in many of the key topic areas of the management and organization sciences, from team cognition (cf., Hambrick, 2007; Healey et al., 2015; Mohammed, Ferzandi, \& Hamilton, 2010) and goal setting theory (Latham \& Piccolo, 2012; Shantz \& Latham, 2009) to the psychological foundations of strategic management (Hodgkinson \& Healey, 2011; Powell, 2011; Powell, Lovallo, \& Fox, 2011). ${ }^{1}$

Before introducing the various contributions incorporated in this volume, it is instructive to reflect on the impact that these developments are having on methodological advances in MOC more broadly. To this end, following Hodgkinson and Healey (2011), it is analytically convenient to conceive of human cognition in the workplace (and, indeed, human cognition more generally) as ranging along two principal dimensions, namely, nonconscious/automatic versus conscious/deliberative cognition (Dimension 1) and "hot" (high affect) versus "cold" (low affect) cognition (Dimension 2).

As illustrated in Fig. 1, until very recently, the bulk of scholarly attention was centered on but one portion of the available conceptual space: the lower right-hand quadrant of the circumplex, the area depicting low affect, deliberative cognition. In consequence, over a remarkably short time period, the MOC field witnessed a proliferation in the range of techniques being applied in an effort to "map" actors' mental representations of workrelated knowledge, epitomized by the content of Huff's (1990) classic volume (see also Eden \& Spender, 1998; Fiol \& Huff, 1992; Hodgkinson \& Healey, 2008; Hodgkinson \& Sparrow, 2002; Huff \& Jenkins, 2002; Sparrow, 1998; Walsh, 1995). By way of illustration, techniques employed by strategic management researchers to "reveal" actors' mental representations of strategic knowledge of business rivals have ranged from relatively simple procedures that merely require "thought-listing" competitors by name (de Chernatony, Daniels, \& Johnson, 1993; Gripsrud \& Gronhaug, 1985) to semi-structured interviews using hierarchical taxonomic mapping procedures (Calori, Johnson, Sarnin, 1992, 1994; Hodgkinson \& Johnson, 1994; Porac \& Thomas, 1994; Porac, Thomas, \& Baden-Fuller, 1989; Porac, Thomas, Wilson, Paton, \& Kanfer, 1995), from network analysis techniques based on block modeling and related approaches (Lant \& Baum, 1995; Odorici \& Lomi, 2001; Porac et al., 1995) to repertory grid (Daniels, Johnson \& de Chernatony, 1994; Reger, 1990b; Reger \& Huff, 1993; Reger \& Palmer, 1996; Spencer, Peyrefitte, \& Churchman, 2003) and related multidimensional scaling and 


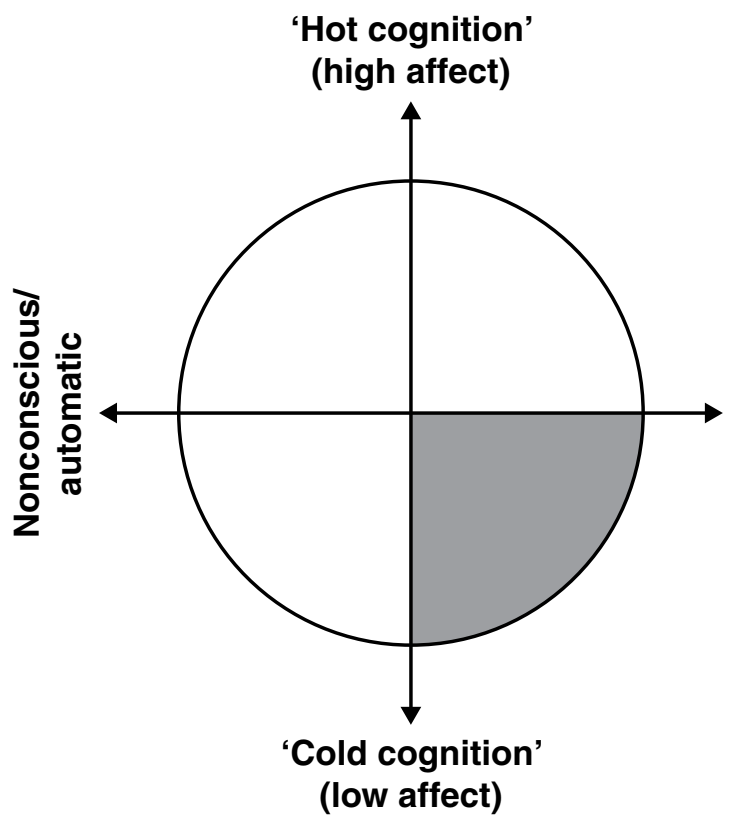

Fig. 1: The Core Dimensions of Managerial and Organizational Cognition. (The Gray-Shaded Area - Cold and Conscious/Deliberative Cognition - Depicts the Subspace That Has Historically Dominated the Preoccupation of MOC Scholars.) Source: Adapted from G.P. Hodgkinson and M.P. Healey (2011, p. 1503). Copyright (C) 2011 John Wiley \& Sons, Ltd. Adapted by kind permission of the publisher.

clustering (Hodgkinson, Padmore \& Tomes, 1991, Hodgkinson, Tomes \& Padmore, 1996; Walton, 1986) techniques, and from fully structured questionnaires based on extant typologies of competitive positioning strategies (Bowman \& Ambrosini, 1997a, 1997b; Bowman \& Johnson, 1992; Dess \& Davis, 1984) to causal mapping techniques (Calori et al., 1992, 1994). A detailed consideration of the relative merits of these techniques lies beyond the scope of the present chapter (for overviews see Eden \& Spender, 1998; Fiol \& Huff, 1992; Hodgkinson, 2005; Hodgkinson \& Healey, 2008; Hodgkinson \& Sparrow, 2002; Huff \& Jenkins, 2002; Sparrow, 1998; Walsh, 1995). As observed by Hodgkinson and Healey (2011, 2014), although these techniques were highly valuable in advancing the early cause of MOC and continue to play an important role in the field's development, this preoccupation with revealing actors' explicit representations of knowledge has ultimately yielded an impoverished portrayal 
of organizational decision-makers as cold and calculating, quasirational cognitive misers (see also Healey \& Hodgkinson, 2017; Powell et al., 2011). These techniques assume that mental representations are born primarily of conscious/deliberation, with little or no regard for the various nonconscious processes that have a fundamental bearing on work-related human behavior, both individual and collective, to say nothing of the emotional content, context, and impact of the substantive issues at hand.

As shown in Fig. 2, the advances outlined above are pushing MOC researchers to move increasingly into the spaces depicted in the other three quadrants of the circumplex model, and in so doing, they are beginning to experiment with a much wider range of methodological techniques (e.g., Johnson, Tolentino, Rodopman, \& Cho, 2010; Latham \& Piccolo, 2012; Laureiro-Martinez, Brusoni, Canessa, \& Zollo, 2015; Powell, 2011; Shantz \& Latham, 2009), as well as adapting established ones (e.g., Hodgkinson, Wright, \& Anderson, 2015), in an effort to address the foregoing challenges. By way of illustration, consider recent advances in the study of the relationship between trait affectivity and work-related performance. Predicated on growing evidence that trait affectivity operates primarily beyond the realm of conscious awareness, Johnson et al. (2010) incorporated implicit (i.e., word fragment completion items) and explicit (i.e., self-report survey items) measures to assess positive and negative affectivity in a study of task performance and organizational citizenship behavior. In line with expectations based on theory, they found that the explicit and implicit measures yielded consistent findings; in each case, positive affectivity was positively related to task performance and citizenship behavior, whereas negative affectivity was negatively related to task performance and positively related to counterproductive behavior. However, the implicit measures predicted significantly greater proportions of variance in the main dependent variables (supervisor-rated criteria reflecting variations in job-related task performance and organizational citizenship behavior), with substantial incremental gains over and above the explicit measures.

As a second illustration, consider the recent work of Latham and colleagues on the motivational effects of subconscious goals on job performance. Goal-setting theory (Locke \& Latham, 1984, $1990,2002)$ has traditionally emphasized the efficacy of goals that are consciously and explicitly set, thereby ensuring that the goals in question are in focal awareness. This is because goal commitment has been viewed as a conscious decision and goal pursuit 


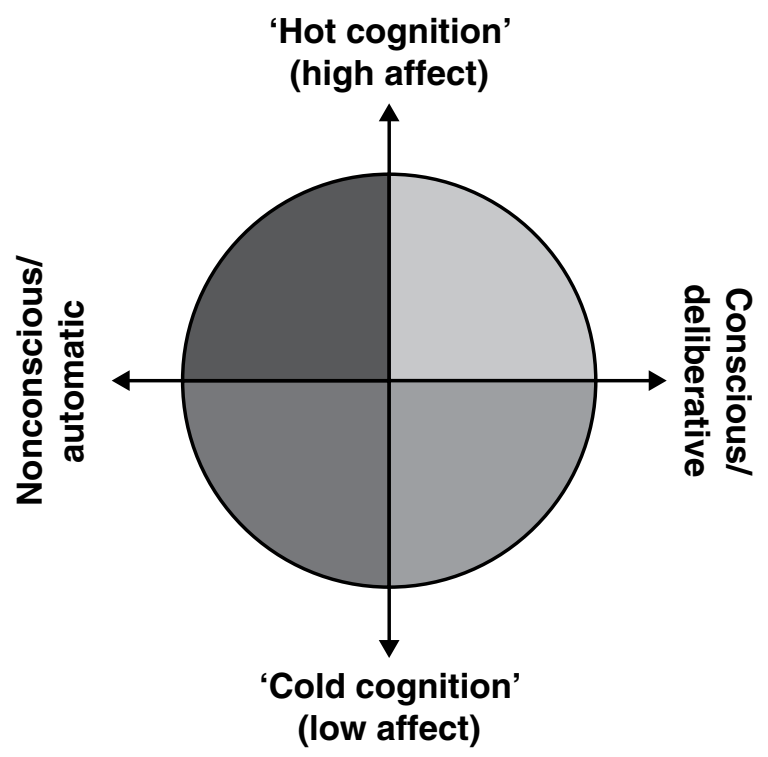

Fig. 2: Expanding the Foci of Managerial and Organizational Cognition. Source: Adapted from G.P. Hodgkinson and M.P. Healey (2011, p. 1503). Copyright

(C) 2011 John Wiley \& Sons, Ltd. Adapted by kind permission of the publisher.

as a function of the conscious monitoring of one's performance toward goal attainment (Latham \& Locke, 2007). However, in a series of studies, Shantz and Latham (2009) have demonstrated the relative power of conscious goals versus primed subconscious goals on job performance (see also Latham \& Piccolo, 2012). In one such study people on their way to work $(n=52)$, who had been shown a photo of a woman winning a race, outperformed on a brainstorming task their counterparts assigned to the control group. A follow-up laboratory experiment $(n=71)$ identified subconscious need for achievement (measured by a projective test) as the mechanism generating these effects. A third study, a field study of call center employees $(n=81)$, which utilized a $2 \times 2$ factorial design (primed goal vs. control group; conscious goal vs. do best goal), observed main effects both for the primed goal and for the conscious goal, in terms of the amount of money solicited from donors.

The more general implication arising from studies such as these is that because the various implicit processes - for example, subconscious goals (Latham \& Piccolo, 2012; Shantz \& Latham, 2009), implicit attitudes (Greenwald \& Banaji 1995; Greenwald, 
McGhee, \& Schwartz, 1998; Greenwald et al., 2002), and implicit affect (Johnson et al., 2010) - that have a major bearing on the behavior of individuals and collectives in the workplace (Healey et al., 2015) operate largely beyond conscious awareness, and hence they are not amenable to reliable introspection (cf., Ericsson \& Simon, 1980; Nisbett \& Ross, 1980; Nisbett \& Wilson, 1977), researchers should incorporate measurement techniques that capture implicit content and processes (cf., Johnson \& Steinman, 2009). Candidate techniques for this purpose include lexical decision tasks such as the ones employed by Johnson and colleagues (2010), implicit association tests, and Stroop tasks (Johnson \& Steinman, 2009).

\section{Overview of the Chapters in this Volume}

We now turn to introduce each of the chapters selected for inclusion in the present volume. In differing ways and to varying extents they each engage with the issues and themes highlighted in this opening chapter.

Building directly on the developments in social neuroscience, dual-process theories, and related areas highlighted above, Mark P. Healey, Mercedes Bleda, and Adrien Querbes explore the possibilities and pitfalls of using computer simulation methods to model the dynamics of affect and cognition in organizations, centered on agent-based modeling (ABM) techniques. Ranked among the most popular of approaches to simulation across the social and behavioral sciences (see, e.g., Axelrod, 1997; Epstein, 2006; Miller \& Page, 2007; Smith \& Conrey, 2007; Squazzoni, Jager, \& Edmonds, 2014), ABM is gathering momentum in the management and organization sciences as a method for increasing the specificity and precision of theory and research (see, e.g., Hughes, Clegg, Robinson \& Crowder, 2012; Miller, 2015). In their chapter, Healey and colleagues argue the case for adopting ABM techniques to improve the level of specificity of cognitive and affective concepts and refine understanding of their interrelationships in organizational theories. Doing so should ultimately yield models of behavior in and of organizations that are more plausible than the ones published presently in the MOC literature and deepen understanding of the generative mechanisms pertaining to multilevel organizational phenomena (cf., Gavetti, Levinthal \& Ocasio, 2007; Healey \& Hodgkinson, 2014, 2015; Hodgkinson \& Healey, 2011, 2014; Puranam, Stieglitz, Osman, \& Pillutla, 2015). 
Continuing the theme of researching the dynamics of emotion in MOC, Timo O. Vuori's chapter reflects on another technique that is showing great promise as an approach for gathering high-quality data in what is clearly a highly sensitive topic area: the open-ended interview. In a refreshingly open account, born of personal experience (Vuori \& Huy, 2016), Vuori offers firsthand advice of how to maximize the likelihood of realizing the interview technique's full potential, especially when dealing with highly experienced and knowledgeable executives and managers. Containing a wealth of penetrating insights and helpful tips that will benefit novices and seasoned researchers alike, he concludes his chapter with a useful annotated guide to further reading.

Drawing on the aforementioned insights of theory and research on implicit social cognition and dual-process theory (e.g., Bargh, 2006; Hodgkinson \& Healey, 2011; Smith \& DeCoster, 2000; Strack \& Deutsch, 2004), Robin Martin, Olga Epitropaki, and Laurie O'Broin's chapter reviews a body of work demonstrating how leadership training interventions can help to facilitate the development of managers' dual-processing capabilities. Whereas, most leadership training programs focus primarily on honing actors' capabilities located in the lower right-hand quadrant of the Hodgkinson and Healey (2011) circumplex model (conscious/deliberative-cold cognition) highlighted in Figs. 1 and 2, Martin and colleagues review a growing body of work demonstrating the efficacy of interventions that address nonconscious/automatic and hot cognition processes (i.e., the additional quadrants highlighted in Figs. 1 and 2). The primary focus of their chapter is to highlight methodological issues pertaining to the design and analysis of studies seeking to enable researchers to infer causality between independent (in this case, training vs. nontraining) and dependent (in this case, follower, team, leader, organizational outcomes) variables and consider some of the major internal and external threats to the validity of findings. Inter-alia, well-designed training interventions can be used to help actors understand their implicit assumptions about leadership and how those assumptions are often in conflict with their espoused theories of action (Argyris \& Schön, 1978). The work reviewed in this chapter demonstrates how, in the absence of such training, individuals may not be fully aware of how their implicit theories of leadership (and followership) shape fundamentally their action tendencies.

One method for gaining insights into the cognitive bases of work-related decision processes by revealing actors' "implicit" 
models of the problem at hand is the experimental technique known as policy capturing (Aiman-Smith, Scullen, \& Barr, 2002; Cooksey, 1996; Karren \& Barringer, 2002). In policy-capturing studies participants are presented with a series of alternative scenarios, in which the key features, referred to as cues, are varied systematically by the researcher, on a scenario $\times$ scenario basis. The overriding goal of such studies is to reveal which particular cue combinations (the independent variables) predict which particular decision outcomes (the dependent variable), typically by means of multiple regression analysis. Like the techniques reviewed in the previous chapter by Martin and colleagues, demonstrating a conflict between leaders' implicit assumptions and their espoused theories of action, policy-capturing studies often reveal that decision-makers' "theories in use" (Argyris \& Schön, 1974; Tyler \& Steensma, 1998) - what they actually do - is at variance with what they say they do (see, e.g., German, Fortin \& Read, 2016; Wang, Gao, Hodgkinson, Rousseau, \& Flood, 2015; Webster \& Treviño, 1995; Zedeck \& Kafry, 1977). In highlighting the inaccuracy of decision-makers' explicit understanding of their policies, such studies call into question the validity of direct self-report techniques for studying human decision processes (cf., Ericsson \& Simon, 1980; Nisbett \& Ross, 1980; Nisbett \& Wilson, 1977). Karen Nokes and Gerard P. Hodgkinson's chapter provides an overview of the background theory underpinning the policy-capturing technique, considers the critical issues that need to be addressed when designing policy-capturing studies, and offers practical advice regarding some of the common pitfalls of the technique and ways of avoiding them.

The next chapter, by Charlotte Reypens and Sheen S. Levine, argues the case for combining behavioral experiments with protocol analysis as a basis for capturing work-related cognition in action. As in the case of policy-capturing studies, combining protocol analysis with the laboratory method enables MOC researchers to create an environment that simulates the essence of management decision-making, but does so in a manner that affords experimental control, thereby aiding clarity and enabling causal inference. As explained by Reypens and Levine, with the proviso that researchers adhere carefully to the guidelines outlined in Protocol Analysis: Verbal Reports as Data (Ericsson \& Simon, 1984, 1993), "thinking aloud" does not interfere with participants' actual thoughts nor does it interfere with their ability to perform tasks, a premise supported by recent meta-analytic findings (Fox, Ericsson, \& Best, 2011). Through a series of 
illustrations of their own work, they demonstrate the value of combining protocol analysis with laboratory tasks as a vehicle for theory building and theory testing. Like many of the other chapters in this volume, this one offers many useful insights and tips, ranging from how to design such studies, to the collection of data and its analysis and interpretation using a combination of quantitative and qualitative techniques.

The next two chapters report on advances pertaining to causal mapping techniques. These techniques fall within a general class of cognitive mapping procedures that Huff (1990, p. 16) categorized as methods for revealing understanding of "influence, causality and system dynamics." As implied by their name, causal mapping techniques are designed to capture actors' causal belief systems. In their most basic form, cause maps can be depicted graphically using the medium of the influence diagram (Diffenbach, 1982). Adopting this approach, variables are depicted as nodes in a network, interconnected by a series of arrow-headed pathways, terminating in each case on the dependent variable(s), the arrowheads depicting the directions of causality. An emphasis on action, focusing on the perceived inter-relationships between a given situation and its antecedents and likely consequences, renders this approach to cognitive mapping particularly attractive both for descriptive research purposes and as a basis for intervening prescriptively in organizational decision processes (see, e.g., Eden \& Ackermann, 1998; Hodgkinson, Bown, Maule, Glaister, \& Pearman, 1999). Despite the widespread popularity of causal mapping techniques, there is currently no consensus within the literature concerning the most appropriate way to elicit actors' causal belief systems (for an overview of alternative approaches, see Hodgkinson \& Clarkson, 2005). Mauri Laukkanen's chapter reports on recent advances in comparative causal mapping based on his CMAP3 system of software, one of a range of alternative computer software packages and related approaches presently available for undertaking causal mapping studies for varying purposes (cf., Clarkson \& Hodgkinson, 2005; Eden \& Ackermann, 1998; Eden, Ackermann, \& Cropper, 1992; Hodgkinson, Maule, \& Bown, 2004; Markoczy \& Goldberg, 1995; Nadkarni $\&$ Narayanan, 2005). His chapter demonstrates the versatility of the CMAP3 system vis-à-vis its main alternatives and offers many useful insights and handy tips for the would-be user of causal mapping techniques in general. Continuing the theme of comparative causal mapping, the chapter by Gail P. Clarkson and Mike A. Kelly reports on the use of a Monte Carlo method of simulation, 
to empirically estimate parameterized probability outcomes, as a foundation for advancing understanding of the behavior of cause maps. Fundamental work such as this is vital for ascertaining the extent to which varying structures of cause maps elicited in studies seeking to advance MOC topics such as decision-making, reasoning, and the links between actors' revealed mental representations and behavior, reflect meaningful differences of substantive concern, as opposed to mere variations that might be expected on a purely random basis. Clarkson and Kelly's chapter provides an important first step in enabling the comparison of the observed structural characteristics of samples of cause maps with the structural characteristics expected (in terms of the mean and standard deviation values for a population of random cognitive maps) in respect of seven of the most commonly adopted structural measures currently in use.

Another highly set of popular and versatile techniques that has been foundational to the development of the MOC field is the collection of techniques known as repertory grid (see, e.g., Daniels, de Chernatony, \& Johnson, 1995; Ginsberg, 1989; Hodgkinson, 1997, 2005; Hodgkinson, Wright, \& Anderson, 2015; Reger, 1990a, 1990b; Reger \& Huff, 1993; Reger \& Palmer, 1996; Spencer et al., 2003; Wright, Paroutis, \& Blettner, 2013). Pioneered by Kelly (1955) as an idiographic approach for revealing insights into the cognitive maps of clients in the context of clinical psychology, over the years repertory grid techniques have come to enjoy considerable success in applied studies of social cognition in a wide variety of domains well beyond their clinical roots and idiographic origins (for a recent overview of applications in strategic management, see Hodgkinson, Wright, \& Paroutis, 2016). In a highly reflective and reflexive chapter, Robert P. Wright considers afresh Kelly's (1955) personal construct theory. This theory was foundational to the development of the repertory grid as a technique that celebrated the uniqueness of people; revisiting it, Wright implores researchers to reconsider its implications for understanding the "why" of people's thinking, feeling, and acting centred on Kelly's all-important preoccupation with the notion of "anticipation."

The next two chapters consider the implications of some of the many exciting developments in social neuroscience, alluded to above, for advancing the cause of MOC (see also Waldman \& Balthazard, 2015; Waldman, Ward, \& Becker, 2017). Sebastiano Massaro's chapter provides a much-needed overview of several of the main neuroscience techniques that are being brought to 
bear increasingly on the analysis of MOC, namely, functional magnetic resonance imaging (fMRI), electroencephalography, magnetoencephalography, heart rate variability, and skin conductance response. He then considers the implications of these techniques for developing a more embodied and socially situated perspective on MOC (cf., Butler, Lee, \& Senior, 2017; Healey \& Hodgkinson, 2014, 2015). The chapter by Daniella LaureiroMartinez centers on what is currently one of the most popular of neuroscience techniques in MOC, fMRI, and advocates using it in conjunction with the aforementioned think aloud technique known as verbal protocol analysis, as a vehicle for pushing the frontiers of MOC away from its historical preoccupation with the conscious cold cognition quadrant of the Hodgkinson and Healey (2011) circumplex model to embrace all four of its quadrants. Laureiro-Martinez proposes a research agenda that promises to illuminate how the full range of functions depicted in the circumplex model unfold overtime, moving the MOC field's focus away from a static, two-dimensional analysis, toward a three-dimensional analysis, depicted as a series of circles stacked within a more complex cylindrical model.

In the closing chapter of this volume, using the technique of content analysis, Xinran Wang and Rhonda K. Reger report an investigation of the methodological content of 573 publications from two prominent management journals: the Academy of Management Journal (AMJ) and Strategic Management Journal $(S M J)$. Predicated on the premise that MOC should be a fundamental area of inquiry informing all subfields within the field of strategic management, Wang and Reger report a comprehensive examination of the methodological content of all $S M J$ publications $(n=389)$ and macro-level $A M J$ publications $(n=184)$ from 2009 to 2013. Their analysis contributes to an emerging stream of research that reflects on the cognitive microfoundations of our editorial practices in the leading scholarly journals in the management and organization studies field more broadly (see, e.g., Baruch. Konrad, Aguinis, and Starbuck, 2008; Clark, Wright, \& Ketchen, 2016; Hodgkinson \& Ford, 2014; Peters, Daniels, Hodgkinson, \& Haslam, 2014; Rousseau, Manning, \& Denyer, 2008 ) and provides invaluable insights into which particular cognitive methods are more or less in vogue in the field of strategic management and what guidance about those methods might be offered to assist MOC scholars in achieving their academic publication goals and advisors seeking to train the next generation of macro-level cognition scholars. 


\section{Conclusion}

In the final analysis, there is no such thing as a perfect method. All of the techniques surveyed above and discussed in the remaining chapters of this volume are beset with limitations. For this reason, researchers have long extolled the virtues of employing multiple methods in an effort to triangulate findings (Greene, 2007; Jick, 1979; Molina-Azorin et al., 2017), a strategy that we and our contributors endorse wholeheartedly. As the chapters incorporated in the present volume so aptly demonstrate, the MOC field has advanced considerably over the $25+$ years that have passed all too quickly since the publication of the Huff (1990) volume. The chapters we have assembled demonstrate not only how far the field has advanced, but also how much more has yet to be accomplished.

\section{Note}

1. As observed by Pratt and Crosina (2016), each of these developments has its respective detractors and controversies. In respect of neuroscience, see, for example, Lindebaum and Zundel (2013), Healey and Hodgkinson $(2014,2015)$, and Waldman et al. (2017); in respect of dualprocess theories, see, for example, Kruglanski and Gigerenzer (2011) and Evans and Stanovich (2013); in respect of implicit attitudes, see, for example, Blanton, Jaccard, Christie, \& Gonzales (2007), Nosek and Sriram (2007), and Oswald, Mitchell, Blanton, Jaccard, \& Tetlock (2013); and in respect of priming, see, for example, Doyen, Klein, Pichon, \& Cleeremans (2012), Shanks et al. (2013), and Cesario (2014).

\section{References}

Aiman-Smith, L., Scullen, S. E., \& Barr, S. H. (2002). Conducting studies of decision making in organizational contexts: A tutorial for policy-capturing and other regression-based techniques. Organizational Research Methods, 5, 388-414.

Argyris, C., \& Schön, D. A. (1974). Theory in practice: Increasing professional effectiveness. Oxford: Jossey-Bass.

Argyris, C., \& Schön, D. (1978). Organizational learning: A theory of action perspective. Reading, MA: Addison Wesley.

Ashkansey, N. M., Humphrey, R. H., \& Huy, Q. N. (2017). Integrating emotions and affect in theories of management. Academy of Management Review, 42, 175-189.

Axelrod, R. (1997). Advancing the art of simulation in the social sciences. In R. Conte, R. Hegselmann \& P. Terna (Eds.), Simulating social phenomena (pp. 21-40). Berlin Heidelberg: Springer. 
Bargh, J. A. (Ed.). (2006). Social psychology and the unconscious: The automaticity of higher mental processes. Florence, KY: Psychology Press.

Bargh, J. A., \& Williams, E. L. (2006). The automaticity of social life. Current Directions in Psychological Science, 15, 1-4.

Bargh, J. A., Chen, M., \& Burrows, L. (1996). Automaticity of social behavior: Direct effects of trait construct and stereotype activation on action. Journal of Personality and Social Psychology, 71, 230-244.

Baruch, A. M., Konrad, H., Aguinis, \& Starbuck, W. H. (Eds.). (2008). Opening the Black Box of editorship. Basingstoke: Palgrave Macmillan.

Blanton, H., Jaccard, J., Christie, C., \& Gonzales, P. M. (2007). Plausible assumptions, questionable assumptions and post hoc rationalizations: Will the real IAT, please stand up? Journal of Experimental Social Psychology, 43, 399-409.

Bowman, C., \& Ambrosini, V. (1997a). Perceptions of strategic priorities, consensus and firm performance. Journal of Management Studies, 34, 241-258.

Bowman, C., \& Ambrosini, V. (1997b). Using single respondents in strategy research. British Journal of Management, 8, 119-131.

Bowman, C., \& Johnson, G. (1992). Surfacing competitive strategies. European Management Journal, 10, 210-219.

Butler, M. J. R., Lee, N., \& Senior, C. (2017). Organizational cognitive neuroscience drives theoretical progress, or: The curious case of the straw man murder. Human Relations, 70, 1171-1190.

Calori, R., Johnson, G., \& Sarnin, P. (1992). French and British top managers' understanding of the structure and dynamics of their industries: A cognitive analysis and comparison. British Journal of Management, 3, 61-78.

Calori, R., Johnson, G., \& Sarnin, P. (1994). CEOs' cognitive maps and the scope of the organization. Strategic Management Journal, 15, 437-457.

Cesario, J. (2014). Priming, replication, and the hardest science. Perspectives on Psychological Science, 9, 40-48.

Chaiken, S., \& Trope, Y. (Eds.). (1999). Dual-process theories in social psychology. New York, NY: Guilford Press.

Clark, T., Wright, W., \& Ketchen, D. (Eds.). (2016). How to publish in the best management journals. Cheltenham and Northampton, MA: Edward Elgar.

Clarkson, G. P., \& Hodgkinson, G. P. (2005). Introducing Cognizer ${ }^{\mathrm{TM}}$ : A comprehensive computer package for the elicitation and analysis of cause maps. Organizational Research Methods, 8, 317-341.

Cooksey, R. W. (1996). Judgment analysis: Theory, methods, and applications. San Diego, CA: Academic Press.

Dane, E., \& Pratt, M. G. (2007). Exploring intuition and its role in managerial decision making. Academy of Management Review, 32, 33-54.

Daniels, K., DeChernatony, L., \& Johnson, G. (1995) Validating a method for mapping managers' mental models of competitive industry structures. Human Relations, 48(8), 975-991.

Daniels, K., Johnson, G., \& de Chernatony, L. (1994). Differences in managerial cognitions of competition. British Journal of Management, 5, S21-S29. 
de Chernatony, L., Daniels, K., \& Johnson, G. (1993). A cognitive perspective on managers' perceptions of competition. Journal of Marketing Management, 9, 373-381.

Dess, G. G., \& Davis, P. S. (1984). Porter's (1980) generic strategies as determinants of strategic group membership and organizational performance. Academy of Management Journal, 27, 467-488.

Diffenbach, J. (1982). Influence diagrams for complex strategic issues. Strategic Management Journal, 3, 133-146.

Doyen, S., Klein, O., Pichon, C.-L., \& Cleeremans, A. (2012). Behavioral priming: It's all in the mind, but whose mind? PLOS ONE, 7, e29081.

Eden, C., \& Ackermann, F. (1998). Making strategy: The journey of strategic management. London: Sage.

Eden, C., \& Spender, J.-C. (Eds.). (1998). Managerial and organizational cognition: Theory, methods and research. London: Sage.

Eden, C., Ackermann, F., \& Cropper, S. (1992). The analysis of cause maps. Journal of Management Studies, 29, 309-324.

Epstein, S. (1994). Integration of the cognitive and the psychodynamic unconscious. American Psychologist, 49, 709-724.

Epstein, J. M. (2006). Generative social science: Studies in agent-based computational modeling. Princeton, NJ: Princeton University Press.

Ericsson, K., \& Simon, H. (1980). Verbal reports as data. Psychological Review, $87,215-251$.

Ericsson, K. A., \& Simon, H. A. (1984). Protocol analysis: Verbal reports as data. Cambridge, MA: The MIT Press.

Ericsson, K. A., \& Simon, H. A. (1993). Protocol analysis: Verbal reports as data (Rev. ed.). Cambridge, MA: MIT Press.

Evans, J. S. B. T. (2007). On the resolution of conflict in dual process theories of reasoning. Thinking \& Reasoning, 13, 321-339.

Evans, J. S. B. T. (2008). Dual-processing accounts of reasoning, judgment, and social cognition. Annual Review of Psychology, 59, 255-278.

Evans, J. S. B.T., \& Stanovich, K. E. (2013). Dual-process theories of higher cognition: Advancing the debate. Perspectives on Psychological Science, 8, 223-241.

Ferguson, M. J., \& Bargh, J. A. (2004). Liking is for doing: The effects of goal pursuit on automatic evaluation. Journal of Personality and Social Psychology, 87, 557-572.

Fiol, C. M., \& Huff, A. S. (1992). Maps for managers. Where are we? Where do we go from Here? Journal of Management Studies, 29, 267-285.

Fox, M. C., Ericsson, K. A., \& Best, R. (2011). Do procedures for verbal reporting of thinking have to be reactive? A meta-analysis and recommendations for best reporting methods. Psychological Bulletin, 137(2), 316.

Gavetti, G., Levinthal, D., \& Ocasio, W. (2007). Neo-carnegie: The Carnegie school's past, present, and reconstructing for the future. Organization Science, 18(3), 523-536.

German, H., Fortin, M., \& Read, D. (2016). Justice judgments: Individual selfinsight and between- and within-person consistency. Academy of Management Discoveries, 2, 33-50. 
Ginsberg, A. (1989). Construing the business portfolio: A cognitive model of diversification. Journal of Management Studies, 26, 417-438.

Greene, J. C. (2007). Mixed methods in social inquiry. San Francisco, CA: Jossey-Bass.

Greenwald, A. G., \& Banaji, M. R. (1995). Implicit social cognition: Attitudes, self-esteem, and stereotypes. Psychological Review, 102, 4-27.

Greenwald, A. G., McGhee, D. E., \& Schwartz, J. L. K. (1998). Measuring individual differences in implicit cognition: The implicit association test. Journal of Personality and Social Psychology, 74, 1464-1480.

Greenwald, A. G., Banaji, M. R., Rudman, L. A., Farnham, S. D., Nosek, B. A., \& Mellott, D. S. (2002). A unified theory of implicit attitudes, stereotypes, selfesteem, and self-concept. Psychological Review, 109, 3-25.

Gripsrud, G., \& Gronhaug, K. (1985). Structure and strategy in grocery retailing: A sociometric approach. Journal of Industrial Economics, XXXIII, 339-347.

Hambrick, D. C. (2007). Upper Echelons theory: An update. Academy of Management Review, 32, 334-343

Healey, M. P., \& Hodgkinson, G. P. (2014). Rethinking the philosophical and theoretical foundations of organizational neuroscience: A critical realist alternative. Human Relations, 67, 765-792.

Healey, M. P., \& Hodgkinson, G. P. (2015). Toward a theoretical framework for organizational neuroscience. In D. A. Waldman \& P. A. Balthazard (Eds.), Organizational neuroscience (Monographs in Leadership and Management, Vol. 7, pp. 51-81). Bingley: Emerald.

Healey, M. P., \& Hodgkinson, G. P. (2017). Making strategy hot. California Management Review, 59(3), 109-134.

Healey, M. P., Vuori, T., \& Hodgkinson, G. P. (2015). When teams agree while disagreeing: Reflexion and reflection in shared cognition. Academy of Management Review, 40, 399-422.

Hodgkinson, G. P. (1997). Cognitive inertia in a turbulent market: The case of UK residential estate agents. Journal of Management Studies, 34, 921-945.

Hodgkinson, G. P. (2005). Images of competitive space: A study of managerial and organizational strategic cognition. Basingstoke: Palgrave Macmillan.

Hodgkinson, G. P., \& Clarkson, G. P. (2005). What have we learned from almost thirty years of research on causal mapping? Methodological lessons and choices for the information systems and information technology communities. In V. K. Narayanan \& D. J. Armstrong (Eds.), Causal mapping for research in information technology (pp. 46-79). Hershey, PA: Idea Group.

Hodgkinson, G. P., \& Ford, K. (2014). Narrative, meta-analytic, and systematic reviews: What are the differences and why do they matter? Journal of Organizational Behavior, 35, S1-S5.

Hodgkinson, G. P., \& Healey, M. P. (2008). Cognition in organizations. Annual Review of Psychology, 59, 387-417.

Hodgkinson, G. P., \& Healey, M. P. (2011). Psychological foundations of dynamic capabilities: Reflexion and reflection in strategic management. Strategic Management Journal, 32, 1500-1516. 
Hodgkinson, G. P., \& Healey, M. P. (2014). Coming in from the cold: The psychological foundations of radical innovation revisited. Industrial Marketing Management, 43, 1306-1313.

Hodgkinson, G. P., \& Johnson, G. (1994). Exploring the mental models of competitive strategists: The case for a processual approach. Journal of Management Studies, 31, 525-551.

Hodgkinson, G. P., \& Sparrow, P. R. (2002). The competent organization: A psychological analysis of the strategic management process. Buckingham: Open University Press.

Hodgkinson G. P., Langan-Fox. J., \& Sadler-Smith, E. (2008). Intuition: A fundamental bridging construct in the behavioural sciences. British Journal of Psychology, 99, 1-27.

Hodgkinson, G. P., Maule, A. J., \& Bown, N. J. (2004). Causal cognitive mapping in the organizational strategy field: A comparison of alternative elicitation procedures. Organizational Research Methods, 7, 3-26.

Hodgkinson, G. P., Padmore, J., \& Tomes, A. E. (1991). Mapping consumers' cognitive structures: A comparison of similarity trees with multidimensional scaling and cluster analysis. European Journal of Marketing, 25(7), 41-60.

Hodgkinson, G. P., Tomes, A. E., \& Padmore, J. (1996). Using consumers' perceptions for the cognitive analysis of corporate-level competitive structures. Journal of Strategic Marketing, 4, 1-22.

Hodgkinson, G. P., Wright, R. P., \& Anderson, J. (2015). Emotionalizing strategy research with the repertory grid technique: Modifications and extensions to a robust procedure for mapping strategic knowledge. In G. Giovanni \& W. Ocasio (Eds.), Advances in strategic management - volume 32: Cognition and strategy (pp. 505-547). Bingley: Emerald.

Hodgkinson, G. P., Wright, R. P., \& Paroutis, S. (2016). Putting numbers to words in the discernment of meaning: Applications of repertory grid in strategic management. In G. B. Dagnino \& M. C. Cinici (Eds.), Research methods for strategic management (pp. 201-226). London: Routledge.

Hodgkinson, G. P., Bown, N. J., Maule, A. J., Glaister, K. W., \& Pearman, A. D. (1999). Breaking the frame: An analysis of strategic cognition and decision making under uncertainty. Strategic Management Journal, 20, 977-985.

Huff, A. S. (Ed.)(1990). Mapping strategic thought. Chichester: Wiley.

Huff, A. S., \& Jenkins, M. (Eds.). (2002). Mapping strategic knowledge. London: Sage.

Hughes, H. P., Clegg, C. W., Robinson, M. A., \& Crowder, R. M. 2012. Agentbased modelling and simulation: The potential contribution to organizational psychology. Journal of Occupational and Organizational Psychology, 85, 487-502.

Jick, T. D. (1979). Mixing qualitative and quantitative methods: Triangulation in action. Administrative Science Quarterly, 24(4), 602-611.

Johnson, R. E., \& Steinman, L. (2009). The use of implicit measures for organizational research: An empirical example. Canadian Journal of Behavioural Science, 41, 202-212.

Johnson, R. E., Tolentino, A., Rodopman, O. B., \& Cho, E. (2010). We (sometimes) know not how we feel: Predicting job performance with an implicit measure of trait affectivity. Personnel Psychology, 63, 197-219. 
Kahneman, D. (2011). Thinking, fast and slow. London: Allen Lane.

Karren, R. J., \& Barringer, M. W. (2002). A review and analysis of the policycapturing methodology in organizational research: Guidelines in research and practice. Organizational Research Methods, 5, 337-361.

Kelly, G. (1955). The psychology of personal constructs Vol. 1. London: Norton. Kruglanski, A. W., \& Gigerenzer G. (2011). Intuitive and deliberate judgments are based on common principles. Psychological Review, 118, 97-109.

Lant, T. K., \& Baum, J. C. (1995). Cognitive sources of socially constructed competitive groups: Examples from the Manhattan Hotel Industry. In W. R. Scott \& S. Christensen (Eds.), The institutional construction of organizations: International and longitudinal studies. Thousand Oaks, CA: Sage.

Latham, G. P., \& Locke, E. A. (2007). New developments in and directions for goal setting research. European Psychologist, 12, 290-300.

Latham, G. P., \& Piccolo, R. F. (2012). The effect of context-specific versus nonspecific subconscious goals on employee performance. Human Resource Management, 51(4), 535-548.

Laureiro-Martinez D., Brusoni S., Canessa N., \& Zollo M. (2015). Understanding the exploration-exploitation dilemma: An fMRIstudy of attention control and decision-making performance. Strategic Management Journal, 36, 319-338. Lieberman, M. D. (2007). Social cognitive neuroscience: A review of core processes. Annual Review of Psychology, 58, 259-289.

Lindebaum, D., \& Zundel, M. (2013). Not quite a revolution: Scrutinizing organizational neuroscience in leadership studies. Human Relations, 66, 857-877.

Locke, E. A., \& Latham, G. P. (1984). Goal setting: A motivational technique that works. Englewood Cliffs, NJ: Prentice Hall.

Locke, E. A., \& Latham, G. P. (1990). A theory of goal setting and task performance. Englewood Cliffs, NJ: Prentice Hall.

Locke, E. A., \& Latham, G. P. (2002). Building a practically useful theory of goal setting and work motivation: A 35 year odyssey. American Psychologist, $57,705-717$.

Loewenstein, G., Rick, S., \& Cohen, J. D. (2008). Neuroeconomics. Annual Review of Psychology, 59, 647-672.

Markoczy, L., \& Goldberg, J. (1995). A method for eliciting and comparing causal maps. Journal of Management, 21, 305-333.

Mohammed, S., Ferzandi, L., \& Hamilton, K. (2010). Metaphor no more: A 15-year review of the team mental model construct. Journal of Management, 36, 876-910.

Molina-Azorin, J. F., Bergh, D. D., Corley, K. G., \& Ketchen, D. J., Jr. (2017). Mixed methods in the organizational sciences: Taking stock and moving forward. Organizational Research Methods, 20(2), 179-192.

Miller, K. D. (2015). Agent-based modeling and organization studies: A critical realist perspective. Organization Studies, 36(2), 175-196.

Miller, J., \& Page, S. (2007). Complex adaptive system. An introduction to computational models of social life. Princeton, NJ: Princeton University Press.

Nadkarni, S., \& Narayanan, V. K. (2005). Validity of the structural properties of text-based causal maps: An empirical assessment. Organizational Research Methods, 8, 9-40. 
Nisbett, R. E., \& Ross, L. (1980). Human inference: Strategies and shortcomings of social judgment. Englewood Cliffs, NJ: Prentice-Hall.

Nisbett, R. E., \& Wilson, T. D. (1977). Telling more than we can know: Verbal reports on mental processes. Psychological Review, 84, 231-259.

Nosek, B. A., \& Sriram, N. (2007). Faulty assumptions: A comment on Blanton, Jaccard, Gonzales, and Christie 2006. Journal of Experimental Social Psychology, 43, 393-398.

Odorici, V., \& Lomi, A. (2001). Classifying competition: An empirical study of the cognitive social structure of strategic groups. In T. K. Lant \& Z. Shapira (Eds.), Organizational cognition: Computation and interpretation. Mahwah, NJ: Erlbaum.

Oswald, F. L., Mitchell, G., Blanton, H., Jaccard, J., \& Tetlock, P. E. (2013). Predicting ethnic and racial discrimination: A meta-analysis of IAT criterion studies. Journal of Personality and Social Psychology, 105, 171-192.

Peters, K., Daniels, K., Hodgkinson, G. P., \& Haslam, S. A. (2014). Experts' judgments of management journal quality: An identity concerns model. Journal of Management, 40, 1785-1812.

Porac, J. F., \& Thomas, H. (1994). Cognitive categorization and subjective rivalry among retailers in a small city. Journal of Applied Psychology, 79, 54-66.

Porac, J. F., Thomas, H., \& Baden-Fuller, C. (1989). Competitive groups as cognitive communities: The case of Scottish knitwear manufacturers. Journal of Management Studies, 26, 397-416.

Porac, J. F., Thomas, H., Wilson, F., Paton, D., \& Kanfer, A. (1995). Rivalry and the industry model of Scottish knitwear producers. Administrative Science Quarterly, 40, 203-227.

Powell, T, C. (2011). Neurostrategy. Strategic Management Journal, 32, 1484-1499.

Powell, T. C., Lovallo, D., \& Fox, C. R. (2011). Behavioral strategy. Strategic Management Journal, 32, 1369-1386.

Pratt, M. G., \& Crosina, E. (2016). The nonconscious at work. Annual Review of Organizational Psychology and Organizational Behavior, 3, 321-347.

Puranam, P., Stieglitz, N., Osman, M., \& Pillutla, M. M. (2015). Modelling bounded rationality in organizations: Progress and prospects. The Academy of Management Annals, 9(1), 337-392.

Reger, R. K. (1990a). Managerial thought structures and competitive positioning. In A. S. Huff (Ed.), Mapping strategic thought. Chichester: John Wiley and Sons.

Reger, R. K. (1990b). The repertory grid for eliciting the content and structure of cognitive constructive systems. In A. S. Huff (Ed.), Mapping strategic thought. Chichester: Wiley.

Reger, R. K., \& Huff, A. S. (1993). Strategic groups: A cognitive perspective. Strategic Management Journal, 14, 103-124.

Reger, R. K., \& Palmer, T. B. (1996). Managerial categorization of competitors: Using old maps to navigate new environments. Organization Science, 7, 22-39.

Rousseau, D. M., Manning, J., \& Denyer, D. (2008). Evidence in management and organizational science: Assembling the field's full weight of scientific knowledge through syntheses. The Academy of Management Annals, 2, 475-515. 
Sadler-Smith, E. (2010). The intuitive mind: Profiting from the power of your sixth sense. Chichester: Wiley.

Shanks, D. R., Newell, B. R., Lee, E. H., Balakrishnan, D., Ekelund, L., et al. (2013). Priming intelligent behavior: An elusive phenomenon. PLoS ONE, 8, e56515.

Shantz, A., \& Latham, G. P. (2009). An exploratory field experiment of the effect of subconscious and conscious goals on employee performance. Organizational Behavior and Human Decision Processes, 109, 9-17.

Sloman, S. A. (1996). The empirical case for two systems of reasoning. Psychological Bulletin, 119, 3-22.

Smith, E. R., \& Conrey, F. R. (2007). Agent-based modeling: A new approach for theory building in social psychology. Personality and Social Psychology Review, 11(1), 87-104.

Smith, E. R., \& DeCoster, J. (2000). Dual-process models in social and cognitive psychology: Conceptual integration and links to underlying memory systems. Personality and Social Psychology Review, 4, 108-131.

Sparrow, J. A. (1998). Knowledge in organizations: Access to thinking at work. London: Sage.

Spencer, B., Peyrefitte, J., \& Churchman, R. (2003). Consensus and divergence in perceptions of cognitive strategic groups: Evidence from the health care industry. Strategic Organization, 1, 203-230.

Squazzoni, F., Jager, W., \& Edmonds, B. (2014). Social simulation in the social sciences: A brief overview. Social Science Computer Review, 32(3), 279-294.

Stanovich, K. E., \& West, R. F. (2000). Advancing the rationality debate. Behavioral and Brain Science, 23, 701-717.

Strack, F., \& Deutsch, R. (2004). Reflective and impulsive determinants of social behavior. Personality and Social Psychology Review, 8, 220-247.

Sund, K. J., Galavan, R. J., \& Huff, A. S. (Eds.) (2016). Uncertainty and strategic decision making. Bingley: Emerald.

Tyler, B. B., \& Steensma, H. K. (1998). The effects of executives' experiences and perceptions on their assessment of potential technological alliances. Strategic Management Journal, 19, 939-965.

Vuori, T. O., \& Huy, Q. N. (2016). Distributed attention and shared emotions in the innovation process how Nokia lost the smartphone battle. Administrative Science Quarterly, 61(1), 9-52.

Waldman, D. A., \& Balthazard, P. A. (Eds.). (2015). Organizational neuroscience (Monographs in Leadership and Management, Vol. 7, pp. 51-81). Bingley: Emerald. Waldman, D. A., Ward, M. K., \& Becker, W. J. (2017). Neuroscience in organizational behavior. Annual Review of Organizational Psychology and Organizational Behavior, 4, 425-444.

Walsh, J. P. (1995). Managerial and organizational cognition: Notes from a trip down memory lane. Organization Science, 6, 280-321.

Walton, E. J. (1986). Managers' prototypes of financial firms. Journal of Management Studies, 23, 679-698.

Wang, S., Gao, Y., Hodgkinson, G. P., Rousseau, D. M., \& Flood, P. C. (2015). Opening the black box of CSR decision making: A policy-capturing study of charitable donation decisions in China. Journal of Business Ethics, 128, 665-683. 
Webster, J., \& Treviño, L. K. (1995). Rational and social theories as complementary explanations of communication media choices: Two policy-capturing studies. Academy of Management Journal, 38, 1544-1572.

Wright, R. P., Paroutis, S. E., \& Blettner, D. P. (2013). How useful are the strategy tools we teach in business schools? Journal of Management Studies, 50(1), 92-125.

Zedeck, S., \& Kafry, D. (1977). Capturing rater policies for processing evaluation data. Organizational Behaviour and Human Performance, 18, 269-294. doi:10.1016/0030-5073(77)90031-9 